\title{
Penerapan Metode Sab'ah Pada Pembelajaran Ashwat Bagi Penutur Bahasa Arab Dewasa Tingkat Pemula di LTQ. Azkiya Kab. Bandung Jawa Barat
}

\section{Susiawati}

Fakultas Bahasa dan Sastra, Universitas Negeri Makassar

E-Mail : susiawati.mqn.mutqin@gmail.com

\section{E-ISSN : $2579-4574$}

P-ISSN : 2549-7359

\begin{abstract}
This research aims to find out the effectiveness of learning model of Ashwat. This research employs qualitative approach with a class action research technique. Results of this research is an Arabic language learning product about contrastive sound to improve Arabic language sound mastery for beginner native. The writer also found significant improvement, before and after learning. The comparative result shows, before the learning process participants who get excellent: $0 \%$, very good: $0 \%$, good: $0 \%$, fair: $30 \%$, minus: $10 \%$, bad: $60 \%$ and after the treatment (post-test) the result is, Excellent: $90 \%$, very good: $10 \%$, good: $0 \%$, fair: $0 \%$, minus: $0 \%$, bad: $0 \%$.
\end{abstract}

Keywords: method, Phonology, beginner native.

\section{https://ojs.unm.ac.id/eralingua}

\section{PENDAHULUAN}

Allah SWT berfirmankan dalam al-qur'an surah al- baqoroh ayat 121 yaitu:

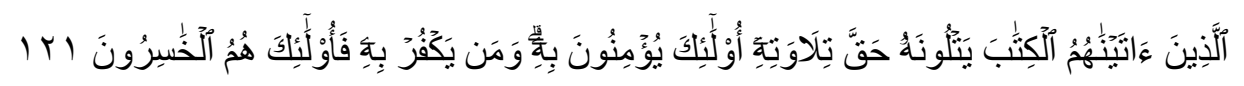

Artinya:

“Orang-orang yang telah Kami berikan Al Kitab (Al-Qur'an) kepadanya, mereka membacanya dengan bacaan yang sebenarnya, mereka itu beriman kepadanya. Dan barangsiapa yang ingkar kepadanya, maka mereka itulah orang-orang yang rugi"

Makna Haqqu tilaawah diartikan juga membaca al-qur'an dengan tartil. Sebagaimana terdapat dalam qs. Al-Muzammil : 4

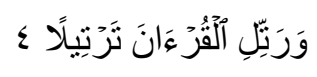

Artinya: "Dan bacalah Al Quran itu dengan perlahan-lahan.”

Rauf (2002: 8) menerangkan bahwa membaca al-qur'an dengan tartil bermakna membaca al-qur'an harus berdasarkan tajwid. Adapun pengertian tajwid secara bahasa adalah at - tahsin yang artinya membaguskan bacaan. Secara terminologis tajwid adalah 
mengeluarkan setiap huruf dari tempat keluarnya huruf dengan memberi hak-hak huruf (sifat-sifat huruf) dan mustahak huruf (sifat yang berhubungan dengan huruf-huruf yang lain). Tiga hal inilah yang membuat keunikan bahasa Arab (karena al -qur'an berbahasa Arab) dari bahasa yang lain. Sehingga jelas perintah Rasulullah Muhammad SAW terkait hal ini dalam hadis dikatakan bahwa : اقر أوا القران بلحون العربيّ و اصو اتها ( Iqrou al -qur'aana biluhuunil 'Arabiyy wa ashwatihaa) artinya bacalahal-qur'an dengan dialek Arab dan fonologi Arab). Rauf (2002 : 10). Menurut Basyir (1980: 146) dialek yang terkenal dari bahasa Arab yang fusha (fasih, benar) sebagai dasarnya adalah dialek Quraisy

Permasalahan berbahasa Arab yang sering dijumpai adalah pengucapan huruf yang tidak sesuai dengan dialek dan fonologi bahasa Arab. Banyak kita jumpai faktor bahasa Ibu menjadi salah satu faktor kesulitan berbahasa Arab khususnya bagi penutur pemula dewasa. Selain itu juga kemampuan pengajar dalam mengucapkan huruf-huruf Arab tidak jarang yang diucapkan kurang benar sehingga mempengaruhi istima' (menyimak) siswa menjadi error (salah). Hal serupapun dikatakan oleh Robert Lado dalam Darjowijoyo. (1979) bahwa permasalahan atau fenomena linguistik yang identik dengan bahasa pertama, akan mempercepat proses belajar, sedangkan fenomena yang berbeda akan menjadi penghalang atau penghambat.

Pengucapan yang salah dan berulang akan membentuk karakter bunyi yang salah pada huruf Arab. Khususnya pada orang dewasa penutur Indonesia karena pengaruh bahasa Ibu (dialek Melayu, Sunda, Jawa, Makassar, Bugis dan lainnya) sehingga berpengaruh terhadap bunyi huruf Arab. Hal ini sesuai dengan teori belajar bahasa yang dikemukakan oleh Skinner dalam Chaer (2009: 91).yaitu operant conditioning yang menunjukkan pada pengkondisian atau pembiasaan. Proses pemerolehan bahasa pertama sebagai peran peniruan (imitation) adalah hal yang sangat penting. Bagi Skinner perilaku berbahasa lebih banyak dipengaruhi atau disebabkan oleh rangsangan (stimulus) dari luar serta pengukuhan (reinforcement) dari rangsangan itu. Dia tidak menerima teori kepandaian yang dibawa sejak lahir dalam pembelajaran berbahasa, akan tetapi semata-mata diperoleh sebagai hasil rangsangan dan pengukuhan terhadap rangsangan itu.

Departemen Agama RI (1997 : 79) menjelaskan bahwa terdapat masalah yang bersifat linguistik yaitu mengenali tata bunyi, kosa kata, tata kalimat dan tulisan serta masalah yang bersifat non linguistik yaitu yang menyangkut segi sosio-kultur atau sosial budaya. Hal ini merupakan permasalahan berbahasa yang harus dicarikan jalan keluarnya. Sebagai salah satu solusi dari permasalahan ini maka peneliti berusaha mengerahkan kemampuan sesuai dengan bidang keilmuan bahasa Arab dan al-qur'an. Lembaga Tahsin Tahfidz Al- Qur'an (LTQ) Azkiya yang terletak di Kecamatan Rancaekek Kab. Bandung Jawa Barat sebagai tempat peneliti mengeksperimenkan metode ini dan sekaligus sebagai penggagas metode ini tahun 2013. Metode sab'ah dalam pengajaran ashwat ini dikhususkan untuk mengajarkan ashwat (fonologi Arab) bagi penutur pemula dalam berbahasa Arab secara praktis tanpa banyak teori fonologi yang biasanya berbelitbelit. 


\section{MODEL PENGAJARAN ASHWAT DENGAN MENGGUNAKAN METODE SAB'AH DI LTQ AZKIYA}

Pengajaran ashwat menurut Tu'aimah (1989 : 36) mengemukakan bahwa karakteristik bahasa Arab yang tersusun dari abjad huruf-huruf Arab yang berjumlah 28 huruf itu kaya dengan bunyi-bunyi yang sifatnya sangat bervariasi bila dibandingkan dengan huruf - huruf non Arab. Dari pengamatan peneliti di dapat bahwa pengajaran ashwat yang ada khususnya pada kelas pemula dewasa (pembelajaran ashwat di perguruan tinggi pada mata kuliah ilmu ashwat pada tingkat formal maupun di tempat lain yang sifatnya non formal) lebih difokuskan pada ilmu ashwatnya secara linguistiknya sehingga porsi mengajarkan berbahasa memiliki porsi sedikit. Akibatnya durasi waktu satu semester tidak efektif kalau kita lihat dari segi hasil.

Berbahasa Arab tidak dapat dipisahkan dengan al-qur'an. Maka begitu pula dengan belajar ilmu ashwat, bahasa Arab tidak bisa dipisahkan dengan ilmu tajwid. Bahkan Ilmu tajwid lebih mendetil berkenaan dengan pembahasan sifat-sifat huruf atau karakter-karakter huruf. Rauf (2002: 39) mengatakan bahwa setiap huruf memiliki sifat pokok atau karakter minimal 5 sifat dan maksimal 7 sifat. Dan huruf pun akan terdapat hukum-hukum lain yang berkenaan dengan tebal tipis bacaan (tafkhim, tarqiiq, taglidz). Secara leksikal dalam kamus Munawwir (1984:645) menuliskan bahwa sab'ah berarti tujuh, dan ketika dibaca sabba'a berarti melipatgandakan tujuh. Dan demikian juga yang dipahami penulis bahwa sab'ah berarti banyak, berlipat ganda. Sehingga diharapkan akan banyak cara, banyak teknik untuk menghadirkan tercapainya tujuan pembelajaran serta banyak kebaikkan yang lain yang didapat khususnya berkenaan dengan aspek kognitif, afektif dan psikomotorik religi. Pastinya dengan suasana belajar yang interaktif, menyenangkan dan menenangkan.

Adapun penjelasan umum model pembelajaran ashwat di LTQ Azkiya yaitu:

1. Terdapat tujuan pembelajaran secara umum dan khusus. Tujuan umum adalah pembelajaran ashwat bernilai ibadah. Maka akhlaq pengajar dan peserta diperhatikan dalam proses belajar mengajar. Dengan menggunakan pendekatan humanistik bahwa memandang manusia punya sisi kelebihan dan kekurangan. Halhal positif yang dimiliki peserta dapat di eksplore dalam diksi kata dan pengayaan dalam contoh-contoh ashwat. Hal ini akan mempengaruhi kenyamanan dalam proses pembelajaran. Proses belajar mengajar dengan memperhatikan pula biah lugowi (kondisi kebahasaan baik kemampuan berbahasa, tingkatan umur dan strata keilmuan). Penetapan tujuan khusus dalam pengajaran ashwat adalah agar pengucapan setiap huruf sesuai dengan dialek dan bunyi huruf Arab. Penyampaian teori ashwat praktis saja yang disampaikan. Lebih memperbanyak dril atau pengulangan dalam bentuk praktek pengucpana. Sehingga didapatkan peserta benar dalam penyebutan atau pengucapan huruf dengan benar sesuai dengan karakter atau sifat-sifatnya. Peserta tidak dibebani dengan istilah linguistic ilmu ashwat yang berbelit-belit. Hanya disampaikan teori praktis saja. Karena prinsipnya bagi tingkat pemula adalah benar dulu dalam pengucapan. Teori harusnya disampaikan pada level mutaqaddim (mahir berbahasa). 
2. Contoh-contoh yang digunakan adalah mengambil dari huruf-huruf hijaiyyah, frasa, kata, kalimat / ayat yang ada di al-qur'an. Berdasarkan tadarruj (kebertahapan) dalam proses pembelajaran. Mulai dari satu huruf vokal berharokat baru kemudian gabungan dua, tiga huruf atau lebih sampai akhirnya berupa kalimat yang panjang. Contoh-contoh disusun berdasarkan taksonomi (pengklasifikasian) berdasarkan sifat-sifat huruf / karakter-karakter huruf berdasarkan ilmu tajwid..Hal ini berbeda dengan buku-buku pembelajaran ashwat atau tajwid yang telah ada atau metode yang ada telah ada.

3. Interaksi afektif pun diasah dengan memilih ayat yang disesuaikan dengan kondisi ke kinian ke disinian dalam tadabbur (analisis sintesis). Tingkat pemahaman, keilmuan pengajar yang berkenaan dengan contoh-contoh ayat akan sangat menentukan nilai lebih dari sekedar tujuan berbahasa. Ada hidden kurikulum terlihat jelas. Untuk memudahkan pengajar maka dibuatlah materi pengayaan berkenaan dengan contoh-contoh ayat yang sifatnya tadarruj (bertahap). Sehingga bukan saja terlihat aspek kognitif, afektif serta psikomotorik kemampuan berbahasa melainkan juga pemahaman siswa sebagai hamba Allah. Penerapan holistic study / at-ta'liim asysyumuly / pembelajaran menyeluruh yang senantiasa menghubungkan dengan kehidupan dunia akhirat. Latihan yang berulang-ulang minimal diulang 7 kali pengulangan akan membantu dalam istima' (listening), qiro'ah (membaca/menyebutkan) sehingga menjadi penguatan.

4. Teknik pengajaran dengan evaluasi pengucapan di awal, tengah dan akhir menjadi keunggulan tersendiri dari metode ini. Baik evaluasi searah dari pengajar terhadap siswi, maupun evaluasi timbal balik antara sesama siswa serta pengajar. Sehingga peserta/siswa yakin akan kebenaran apa yang diucapkan dan yang didengar.

5. Sentuhan irama murottal al-qur'an khususnya dalam membacakan contoh-contoh dari ayat - ayat al-qur;an akan membuat kesan religius tersendiri. Qiro'ah (bacaan alqur'an) yang dipakai pada metode sab'ah ini adalah berdasarkan qiro'ah Imam 'Ashim riwayat Imam Hafsh.

6. Diterapkannya metode penugasan yaitu dengan membaca Al-qur'an minimal 1 juz sehari serta menghapalkan surah-surah pendek yang telah dicontohkan dan dilatihkan. Hal ini diharapkan peserta terbiasa dengan amalan-amalan sunnah Nabi yaitu mampu mengkhatamkan al-qur'an 30 juz setiap bulan. Serta hal ini juga sebagai bentuk penguatan, pembiasaan dalam pelafalan huruf agar semakin ringan hurufhuruf Arab diucapkan. Wajib sifatnya materi ashwat praktis dipraktekkan berdasarkan kebertahapan materi yang telah disampaikan. Sampai akhirnya pada pertemuan akhir yaitu sekitar 16 kali pertemuan, maka semua teori praktis ilmu tajwid harus diperhatikan dan dikondisikan benar dalam pengucapannya.

7. Bertalaqqi yaitu menyetorkan bacaan. Bacaan yang telah ditugaskan diulang-ulang kemudian disetorkan satu persatu yaitu dengan cara membaca secara langsung di hadapan guru. Sistem setoran personal lebih diutamakan daripada klasikal. Sistem mulaazamah (bertemu langsung dengan guru untuk kemudian diperdengarkan dan dikoreksi bacaan) inilah cara yang dipraktekkan oleh Rasulullah kepada Jibril as, 
begitu juga para sahabat Rasulullah kepada Rasulullah Muhammad SAW sebagaimana dituliskan oleh Toliimaat $(1997,52)$. Adapun pelaksanaan pembelajaran sistem klasikal sifatnya pada penyampaian teori praktis. Sistem klasikal digunakan untuk pra intruksional, intruksional maupun tahap evaluasi ataupun penutup.

\section{METODE PENELITIAN}

Metode dalam penelitian ini adalah metode eksperimen semu atau quasi eksperimental method dengan desain "Pre test-post test Nonequivalen control group" (Sugiono, 2010:116). Langkah pertama yang dilakukan adalah mengadakan pre test. Tujuan dari Pre Test ashwat (tes bunyi) ini dimaksudkan untuk memperoleh informasi tentang tingkat penguasaan lafal bunyi bahasa, kemampuan melafalkan bunyi bahasa itu menyangkut aspek bunyi bahasa yang panjangnya bervariasi, mulai dari yang paling kecil dalam bentuk masing-masing bunyi bahasa, sampai kata-kata lepas, frase, kalimat, dan wacana yang lengkap.. Dan hal serupa pun seperti pendapatnya Hamid (2010:30). Untuk penyediaan data dengan menggunakan metode simak atau observasi sebagaimana dijelaskan Mahsun (2005: 92). Sample yang diambil adalah pengajaran ashwat kelas dewasa tingkat pemula di LTQ Azkiya Kec. Rancaekek Kab. Bandung Jawa Barat.

Bahasa, Pengajaran Ashwat, Pengajaran Tajwid

\section{HASIL DAN PEMBAHASAN}

Nilai Pre Test dan Post Test ashwat berdasarkan skala nilai yang digunakan di LTQ Azkiya menaju pada standar nilai Rauf (1998:22) yaitu:

Tabel 1. Standar Nilai yang Digunakan

\begin{tabular}{cc}
\hline Standar Nilai dalam Angka Kuantitatif & Standar Nilai Dalam Kualitatif \\
\hline $91-100$ & Mumtaz (Istimewa, Fasih ) \\
\hline $81-90$ & Jayyid Jiddan (Baik Sekali) \\
$71-80$ & Jayyid (Baik) \\
\hline $61-70$ & Maqbul (cukup) \\
\hline $51-60$ & Naqish (Kurang, belum lulus) \\
\hline$<50$ & Naqish jiddan (Kurang sekali, Belum lulus)
\end{tabular}

Berdasarkan standar nilai tersebut, maka pada tabel berikut dapat dilihat perbandingan nilai pre-test dan post-test pelajar: 
Tabel 2. Perbandingan Nilai Pre Test dengan Post Test Ashwat di LTQ Azkiya

\begin{tabular}{|c|c|c|c|c|c|}
\hline \multirow{2}{*}{$\begin{array}{c}\text { Nilai } \\
\text { Kuantitatif }\end{array}$} & \multirow{2}{*}{$\begin{array}{c}\text { Nilai } \\
\text { Kualitatif }\end{array}$} & \multicolumn{2}{|c|}{ Pre Test } & \multicolumn{2}{|c|}{ Post Test } \\
\hline & & $\begin{array}{l}\text { Jumlah } \\
\text { Peserta }\end{array}$ & Persentase & $\begin{array}{l}\text { Jumlah } \\
\text { Peserta }\end{array}$ & Persentase \\
\hline $91-100$ & $\begin{array}{c}\text { Mumtaz } \\
\text { (Istimewa, } \\
\text { Fasih ) }\end{array}$ & 0 & $0 \%$ & 18 & $90 \%$ \\
\hline $81-90$ & $\begin{array}{c}\text { Jayyid } \\
\text { Jiddan (Baik } \\
\text { Sekali) }\end{array}$ & 0 & $0 \%$ & 2 & $10 \%$ \\
\hline $71-80$ & Jayyid (Baik) & 0 & $0 \%$ & 0 & $0 \%$ \\
\hline $61-70$ & $\begin{array}{l}\text { Maqbul } \\
\text { (cukup) }\end{array}$ & 6 & $30 \%$ & 0 & $0 \%$ \\
\hline $51-60$ & $\begin{array}{c}\text { Naqish } \\
\text { (Kurang, } \\
\text { belum lulus) }\end{array}$ & 2 & $10 \%$ & 0 & $0 \%$ \\
\hline$<50$ & $\begin{array}{c}\text { Naqish } \\
\text { jiddan } \\
\text { (Kurang } \\
\text { sekali, } \\
\text { Belum lulus) }\end{array}$ & 12 & $60 \%$ & 0 & $0 \%$ \\
\hline
\end{tabular}

Berdasarkan data penelitian di atas, maka dapat disimpulkan bahwa model pembelajaran yang diterapkan dapat meningkatkan prestasi akademik pelajar. Hal tersebut dapat dilihat dari perbandingan nilai pre-test dan post-test. Hasil penelitian ini senada dengan beberapa penelitian sebelumnya yang membuktikan bahwa penggunaan model pembelajaran yang tepat dalam proses pengajaran dapat meningkatkan hasil belajar ataupun prestasi akademik peserta didik (Yusri dkk., 2018; Romadloni dkk., 2017; Mantasiah \& Yusri, 2018; Qalbi dkk., 2017).

\section{KESIMPULAN}

Penerapan metode sab'ah sangat efektif dalam pembelajaran ashwat bagi penutur dewasa tingkat pemula. Hal ini dapat dibuktikan pada bagan 1 dan 2. Nilai pada saat sebelum diadakan eksperimen dengan setelah diadakan eksperimen terdapat perbedaan yang sangat signifikan dalam nilai pre-test dan post-test kelas eksperimen. Berdasarkan temuan dan hasil eksperimen yang dilakukan, ada beberapa rekomendasi yang diusulkan:

1. Metode Sab'ah ini dapat diterapkan di perguruan tinggi dalam mata kuliah Ilmu Ashwat berbasis kemahiran berbahasa tapi bukan untuk kemahiran ilmu tentang bahasa (ashwat). 


\section{Eralingua: Jurnal Pendidikan Bahasa Asing dan Sastra Vol.3, No.1, Maret 2019}

2. Penerapan metode sab'ah dengan strategi pembelajaran yang memberi pengalaman secara langsung membuka kitab suci al-qur'an serta melalui pendekatan humanistic berdasarkan psikologi peserta didik adalah hal yang benar-benar memberi dampak yang sangat positif dalam pencapaian hasil belajar peserta/siswa/mahasiswa.

3. Fokus pembelajaran pada kemahiran berbahasa dalam kefasihan pengucapan berdasarkan ilmu ashwat yang praktis sebagaimana pada metode yang digunakan berdasarkan kajian sifat-sifat huruf pada ilmu tajwid adalah sangat memudahkan pemahaman dan pengaplikasian dalam pengucapan.

4. Kepada pihak LTQ Azkiya agar dapat mempublikasikan metode sab'ah dalam produk luarannya yaitu buku kajian praktis ashwat berbasis ilmu tajwid praktis.

5. Keintegralan metode sab'ah dalam memadukan keilmuan bahasa praktis (linguistik praktis) dengan pemahaman manusia beragama yang beradab diharapkan menjadi solusi bukan saja pada permasalahan kebahasaan tetapi masalah keberagamaan dan kebangsaan.

\section{DAFTAR PUSTAKA}

Al-Qur'an, Hijaz Syamil. (2010). Hijaz Terjemahan Tafsir Per Kata. Bandung: Sygma.

Al-Suyuthy, Abdurrahman Jalaluddin. Tt. Al-Muzhir fi Uluum al-Lughah wa Anwa'ihaa. Beirut Libanon : Daar al-Fikr

Bishir, Kamal Muhammad. (1980). Ilmu Al-Lugoh Al-'Am / Ilmu Al-Ashwat. Mesir: Daar Maarif.

Chaer, Abdul. (2009). Psikolinguistik Kajian Teoritik. Jakarta: Rineka Cipta

Darjowijoyo, Soedjono. (1979). Linguistik di Berbagai Budaya. Bandung: Ganeco.

Departemen Agama RI. (1997). Pedoman Pengajaran Bahasa Arab pada Perguruan Tinggi Agama Islam. Jakarta: Proyek Pengembangan Sistem Pendidikan Agama.

Hamid, Abdul. (2010). Mengukur Kemampuan Bahasa Arab untuk Studi Islam. Malang: UINMALIKI Press.

Mahsun. (2005). Metode Penelitian Bahasa. Jakarta : Rajawali Pers.

Mantasiah, R. (2018, June). Pay It Forward Model in Foreign Language Learning to Increase Student's Self Efficacy and Academic Motivation. In Journal of Physics: Conference Series (Vol. 1028, No. 1, p. 012178). IOP Publishing.

Munawwir, Ahmad Warson. (1984). Al- Munawwir kamus Arab-Indonesia. Yogyakarta: Unit Pengadaan Ponpos Al-Munawwir.

Rauf, Abdul 'Aziz Abdur. (2002). Pedoman Dauroh Alquran (Pengantar Tajwid Aplikatif). Jakarta: Markaz Alquran.

Romadloni, A., \& Mantasiah, R. Intercultural approach in foreign language learning to improve students' motivation. Senior Editors, 61.

Sugiyono. (2010). Metode Penelitian Pendidikan (Pendekatan Kuantitatif, Kualitatif, dan $R$ \&D). Bandung: Alfabeta.

Toliimaat, Abdul Mu'ti Muhammad Riyad. (1997). Al Halaqoot Al-Qur'aaniyyah (Diroosah Manhajiyyah Syaamilah). Jeddah: Daar Nuur Maktabaat. 
Tu'aimah, Rusydi Ahmad. (1989). Ta'lîm al-'Arabiyyah Lighairin-nâthiqîna Biha, Manaahijuhu wa Asaalibuhu, Isiku: Mansyûrat al-Mundazzomah al-Islâmiyyah Littarbiyah wal-‘Ulum wa-tsaqâfah.

Qalbi, U. N., Mantasiah, R., Jufri, J., \& Yusri, Y. (2017). Efektivitas Model Pembelajaran Kooperatif Tipe Teams Games Tournaments dalam Keterampilan Menulis Bahasa Jerman Siswa Kelas XII IPA SMA Negeri 1 Bontonompo Kabupaten Gowa. Indonesian Journal of Educational Studies, 20(1).

Yusri, Y., Mantasiah, R., \& Jufri, J. (2018). The Use Of Two Stay Two Stray Model in English Teaching to Increase Student's Learning Outcome. Journal Of Advanced English Studies, 1(1), 39-43. 